\title{
A Report on Bluetongue Outbreak in Thoothukudi District of Tamilnadu, India
}

\author{
N. Balamurugan ${ }^{1} *$ and T. Mohanapriya ${ }^{2}$ \\ ${ }^{1}$ Veterinary Dispensary, Kayathar, Thoothukudi district 628 952, Department of Animal \\ Husbandry, Tamilnadu, India \\ ${ }^{2}$ Department of Veterinary Pathology, Veterinary College and Research Institute, \\ Tirunelveli- 627 358, TANUVAS, Tamilnadu, India
}

*Corresponding author

\section{A B S T R A C T}

\begin{tabular}{|l|}
\hline K e y w o r d s \\
Bluetongue, \\
Clinical signs, \\
Vaccination, Vector \\
control
\end{tabular}

\section{Introduction}

Bluetongue (BT) is one of the important acute infectious arthropod borne, viral diseases of sheep in south India (Sreenivasulu et al., 1999). The disease is caused by RNA virus (BTV), which belongs to the genus Orbivirus and family Reoviridae. In India there is evidence of 24 antigenic strains, which infect all ruminant species especially small ruminant sheep (Maclachlan and Guthrie, 2010). It is transmitted by the Culicoides spp. (bitting midges). Blue tongue disease occurred during heavy rainfall months makes amiable environment for the vector multiplication (Wilson Aruni et al., 1999). Bluetongue is listed under the category of multiple species diseases by Office International des Epizooties (OIE, 2013). Bluetongue infection is more severe and confined to sheep (Darpel et al., 2007). On an average 2\%-30\% mortality noticed in the infected animals. However the number may reach up to $100 \%$ in sheep (Ilango, 2006). It is the major cause for economic loss in sheep production. The present study deals with the Bluetongue 
outbreak and vector control measures in Thoothukudi district of Tamilnadu.

\section{Materials and Methods}

In Arasankulam village of Kayathar block of Thoothukudi district, Tamilnadu, the sheep flocks showed mortality during november 2015. A total of 18 sheep flocks (5200 Nos.) were investigated in the village. The clinical signs were noted and postmortem was conducted. For disease conformation, the following samples spleen, lymph node, lung, liver, heart, whole blood in EDTA, nasal swabs were sent to Vaccine Research Centre Viral Vaccines, Centre for Animal Health Studies, Madhavaram milk colony, TANUVAS, Chennai - 51, India.

\section{Results and Discussion}

On investigation of infected flock, sheep showed the following clinical signs - high temperature $\left(41.0^{0} \mathrm{C}-41.5^{0} \mathrm{C}\right)$, mucopurulent nasal discharge (Fig. 1), frothy salivation, rhinitis, edema of lips, gums, dental pad and tongue (Fig. 2), bleeding in the gums (Fig. 3), erosion in oral commissure (Fig. 4), wryneck (Fig. 6), necrotic ulcers on lateral side of tongue leads to difficulty in swallowing. Some affected sheep showed foot lesions such as coronitis, inter digital wound (Fig. 5) laminitis and dark red hemorrhagic band just above the coronet, which lead to knee-walking. The

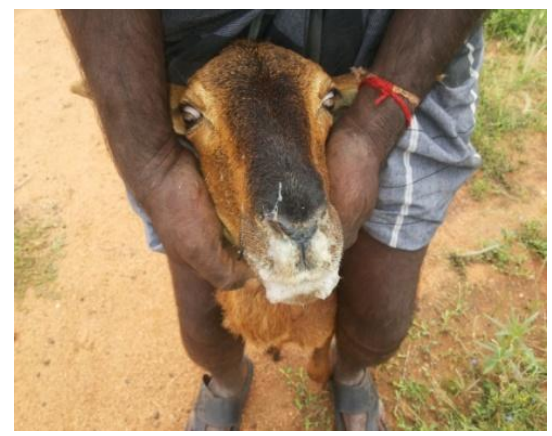

Fig.1 Mucopurulent nasal discharge clinical signs recorded during the investigation were in accordance with Hungerford (1990). The clinical form of the disease was only seen in sheep and in contact goat and cattle were not affected, which was concordance with the findings of Sreenivasulu and Subba Rao (1999). On postmortem examination edema, hemorrhages, swelling and erosions of surface epithelium and necrotic ulcerations of the mucous membranes of oral cavity, cyanosis of tongue were observed. Hyperemia seen in rumen, intestine and kidneys. Hemorrhage on the base of the pulmonary artery was noticed in the carcass which was the pathognomonic lesion of the disease (Fig. 7). The history, clinical signs and the postmortem examination recorded were suggestive of blue tongue disease. The collected samples were processed and confirmed as Bluetongue by RT-PCR.

The affected animals were isolated and treated with electrolyte fluids and antibiotics to control secondary bacterial infection. Oral lesions were cleaned with $1 \%$ potassium permanganate solution and boric powder in glycerin was applied (Yasothai, 2013). For affected animals liquid feed like gruel of rice, bajra and sorghum were given and the animals were under surveillance for 2 weeks. The surrounding sheep flocks were vaccinated with inactivated pentavalent (BTV-1, 2, 10, 16 and 23) bluetongue vaccine (Reddy et al., 2010).

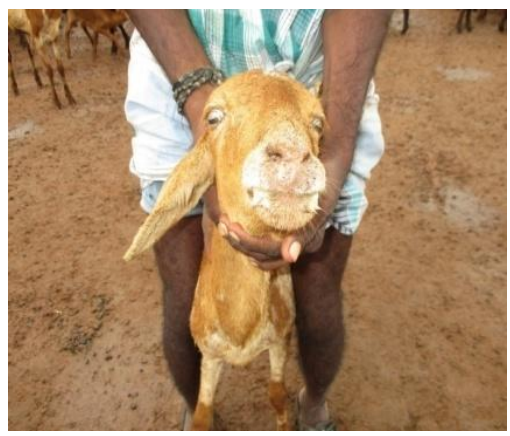

Fig.2 Edema of lips 


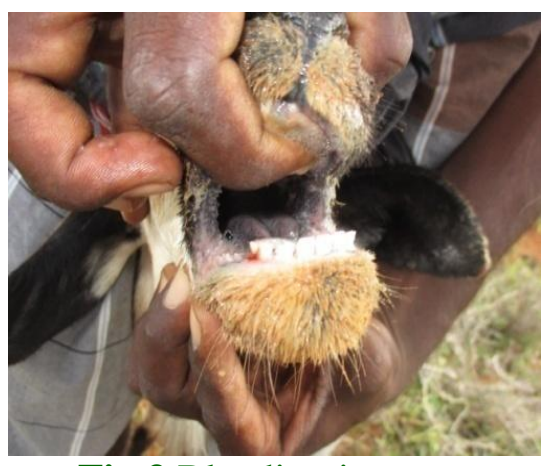

Fig.3 Bleeding in gums

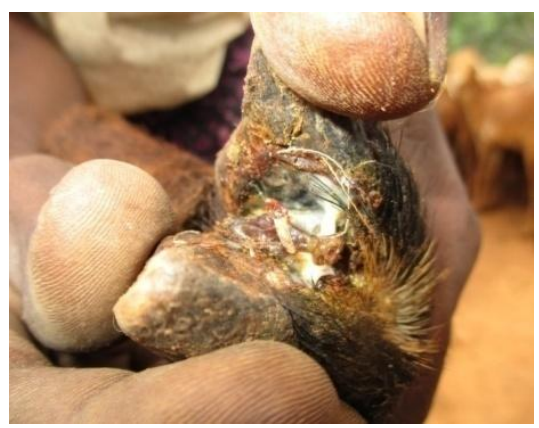

Fig.5 Inter-digital wound

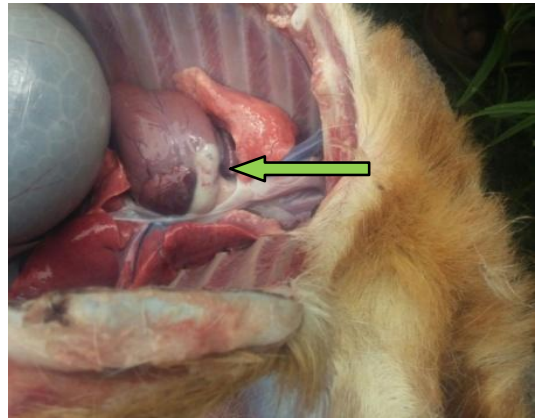

Fig.7 Hemorrhage at the base of pulmonary artery

Water stagnation and dung pits near the sheds were removed to control the vector. Fumigation of animal sheds and its surroundings (Fig-8) was carried out using permethrin and deltamethrin solution (Ilango, 2006) to control vector.

Based on the investigation, it was concluded that sheep flocks were infected with Bluetongue disease. Overall, there was 5\% (260Nos.) morbidity and $0.5 \%$ (24 Nos.) mortality was noticed during the outbreak. In

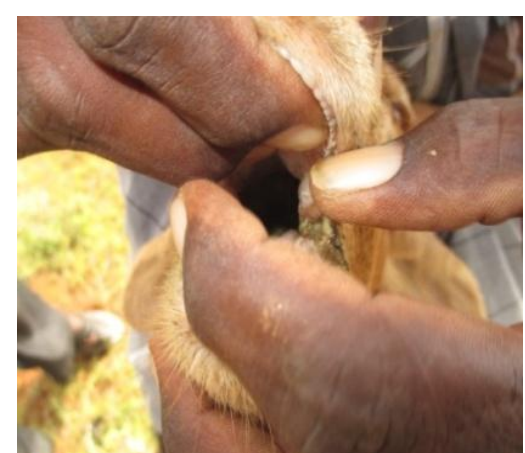

Fig.4 Erosion in oral commissure

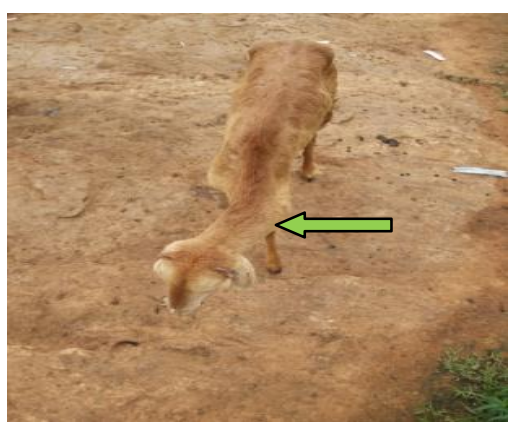

Fig.6 Wry neck condition

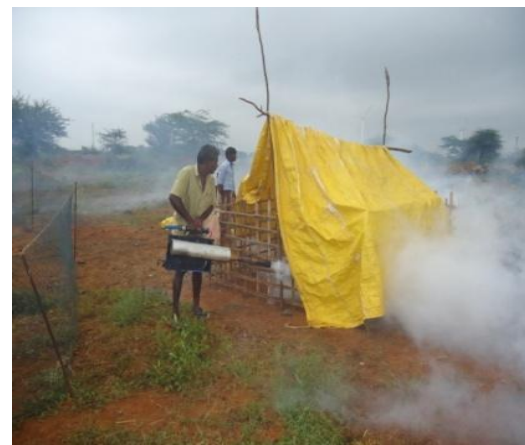

Fig.8 Vector control measure

contact goat and cattle were not affected. The disease occurred during north-east monsoon season which favors the multiplication of vector. Yearly prophylactic vaccination and vector control were advised to prevent future outbreak.

\section{Acknowledgement}

The authors are thankful to the Assistant Director, Animal Disease Intelligence Unit, Thoothukudi District and Director, 
Department of animal husbandry and VVRL, Madhavaram, TANUVAS for their cooperation during the investigation and control of the disease.

\section{References}

Darpel K.E, Batten C. A, Veronesi E, Shaw AE, Anthony S, Bachanek-Bankowska K, Kgosana L, bin-Tarif A, Carpenter S, Müller-Doblies U.U, Takamatsu H.H, Mellor P.S, Mertens P.P and Oura C.A. 2007. Clinical signs and pathology shown by British sheep and cattle infected with bluetongue virus serotype 8 derived from the 2006 outbreak in northern Europe. Veterinary Record. 25; 161(8):253-61

Hungerford, T.G. 1990. Diseases of Livestock. 9th edn. McGraw Hill Book Company,

Ilango, K. 2006. Bluetongue virus outbreak in Tamil Nadu,southern India: Need to study the Indian biting midge vectors, Culicoides latreille (Diptera: Ceratopogonidae), Current Science. Vol. 90, No. 2, 25
MacLachlan and Alan J. Guthrie. 2010. Reemergence of bluetongue, African horse sickness, and other Orbivirus diseases. Veterinary Research. NovDec; 41(6): 35.

Reddy, Y.K.M, Manohar, B.M, Pandey, A.B, Reddy, Y.N, Prasad, G and Chauhan R.S. 2010. Development and evaluation of inactivated pentavalent adjuvanted vaccine for Bluetongue. Indian Veterinary Journal. 87: 434436.

Sreenivasulu, D and Subba Rao, M.V. 1999.

Occurrence of bluetongue in Andhra Pradesh. Indian Veterinary Journal.76: 461-462.

Sydney. pp. 912.

Wilson Aruni, A., Babu, M., Palaniswamy, K.S. and Ebenezer, D. 1999. A report on bluetongue in Tamilnadu. Indian Veterinary Journal. 76: 953-955.

Yasothai, R. 2013. A report on outbreak of blue tongue in Erode district of Tamilnadu. International Journal of Science, Environment and Technology, Vol. 2: $646-648$

\section{How to cite this article:}

Balamurugan, N. and Mohanapriya, T. 2018. A Report on Bluetongue Outbreak in Thoothukudi District of Tamilnadu, India. Int.J.Curr.Microbiol.App.Sci. 7(07): 1086-1089. doi: https://doi.org/10.20546/ijcmas.2018.707.132 